shame transmogrified itself into the Morning Star, is an unpopular view. But it accords with my own experience. Prize three other virtues-honesty, kindness, and courage. The sick need all three. And perhaps the rarest of these is courage.

Let me end on a very personal note. I have thoroughly enjoyed my own life in medicine, and would not have done differently had I the opportunity to begin again. I hope and expect that the service rendered by medicine to society will be such that many will echo the last words of Socrates: "Crito, we owe a cock to Aesculapius; pay it therefore, and do not neglect it."
* "Finally, there should grow the most austere of all mental qualities; I mean the sense for style. It is an aesthetic sense, based on admiration for the direct attainment of a foreseen end, simply and without waste. Style in art, style in literature, style in science, style in logic, style in practical execution have fundamentally the same aesthetic qualities. practical atectye int ane for iy where it is not the The lof quarter-deck, is the love of style as manifested in that study.

"Here we are brought back to the position from which we started, the utility of education. Style, in its finest sense, is the last acquirement
of the educated mind; it is also the most useful. It pervades the whole of the educated mind; it is also the most useful. It pervades the whole
being. The administrator with a sense for style hates waste; the engineer with a sense for style economizes his material; the artisan with a sense for style prefers good work. Style is the ultimate morality of mind." (Whitehead, A. N. (1962) The Aims of Education, Ernest Benn Ltd., London.)

\title{
Use of Gastric Function Tests by British Gastroenterologists
}

\author{
J. H. BARON, J. ALEXANDER WILLIAMS
}

British Medical fournal, 1971, 1, 196-199

\section{Summary}

A questionnaire was used to study the choice and use of gastric function tests by members of the British Society of Gastroenterology.

Pentagastrin has largely replaced older drugs as the stimulant of choice for evoking maximal acid secretion. Insulin tests are being used in situations where they are unlikely to provide useful clinical information. Fewer physicians than surgeons measure gastric secretion, and they use tests less often. The reluctance of physicians to test patients with uninvestigated dyspepsia or gastric ulcer seems justified, but in patients having dyspepsia with negative $x$-ray films, or after gastrectomy or vagotomy, the greater investigative keenness of surgeons seems commendable. Only half the surgeons ever try to assess the completeness of their vagotomies, and in only one-third of this half is it their usual practice. Criticism is made of the practice of routine measurement of acid in patients with duodenal ulcer, and of the use of acid measurements to decide whether a patient should have surgery or which type of operation should be performed.

\section{Introduction}

There is surprisingly little information available on the frequency and type of tests used by clinicians in the investigation of patients. We are particularly interested in gastric function tests, and one of us (Williams, 1969) carried out a pilot survey of their use by British and American surgeons, and Duthie (1969) investigated their use in university departments of surgery in Britain. The opportunity of a complete reexamination of the clinical value of gastric function tests (Baron, 1970) encouraged us to investigate formally their use by gastroenterologists in Britain. Department of Surgery,
Hammersmith Hospital, London W.12

J. H. BARON, D.M., M.R.C.P.

Department of Surgery, the General Hospital, Birmingham 4

J. ALEXANDER WILLIAMS, M.D., CH.M., F.R.c.s.

\section{Method}

In February 1970 a questionnaire (see Appendix) was sent to 259 members and associates of the British Society of Gastroenterology who were thought by their qualifications to be in clinical practice as physicians or surgeons. A reminder letter was sent out in May 1970 and the 202 replies received by the end of June 1970 have been analysed. Deliberately, no space was provided for names, but many doctors did sign their forms. Replies have, however, been treated as anonymous and confidential and no individual views are quoted.

Replies were received from $75 \%$ of the 159 physicians and $82 \%$ of the 100 surgeons, an insignificant difference in response. Blank forms were returned by 19 doctors who stated they were no longer doing sufficient clinical practice to give reasoned replies. The results below are based, therefore, on the useful replies of 108 physicians and 75 surgeons with a specific interest in gastroenterology, who are collectively referred to as "gastroenterologists."

For simplicity of analysis the term "peak acid output" has been taken as synonymous with maximum acid output for acid response to augmented histamine tests, Histalog (ametazole), or pentagastrin. If a doctor used more than one stimulus for peak acid output only the more recent test has been used for analysis.

In each separate clinical situation the rationale for the use of gastric function tests has been analysed, and is followed by our comments on the collective practice of our colleagues. Detailed evidence for these opinions is provided elsewhere (Baron, 1970).

\section{A. Dyspepsia not yet Investigated}

Twenty-six of the 183 gastroenterologists performed acid tests on patients with dyspepsia who had not yet had $x$-ray examination or gastroscopy. Only one in 12 physicians, but one in four of the surgeons, used tests. Surgeons used tests significantly more often than physicians $(P=0.01)$, and only one of the nine physicians who did such tests did them "usually" (see questionnaire Appendix), whereas eight of the 17 surgeons who did these tests performed them usually. Each of the 26 doctors measured peak acid output ( 21 used pentagastrin) and half measured basal acid output as well. Six doctors used insulin tests.

Comment.-Little is to be gained from measuring the acid secretion of patients with dyspepsia who have not had any 
other tests and there is no justification for doing insulin tests in these circumstances.

\section{B. Patients with Duodenal Ulcer}

Four out of five of the gastroenterologists sometimes but not always performed acid tests on patients who were found to have duodenal ulcer on $x$-ray examination. Of this group the surgeons usually employed tests-a highly significant difference from the physicians, who used them infrequently (Table I). Of the 144 doctors who measured peak acid output nearly three-quarters used pentagastrin, one-sixth histamine, and one-twelfth Histalog. Two doctors used gruel test meals, one used insulin, and one measured basal acid output alone (Table II). Almost all of the $\mathbf{9 4}$ doctors who measured basal acid output did so for ane hour, but one in seven doctors collected for 12 hours overnight with or without a one-hour morning basal collection.

Comment.-It does not appear necessary to measure gastric acid in patients with duodenal ulcer unless the diagnosis is in doubt, in which case measurements of basal and peak acid output may help.

\section{C. $X$-ray-Negative Dyspepsia}

Four out of five of the gastroenterologists measured acid in patients with a convincing history of peptic ulcer but a negative barium meal. Of this group only one in five of the physicians but three in five surgeons did tests usually $(P<0.001)$. The tests were similar to those used in patients with duodenal ulcer, and it is of note that $9 \%$ of the doctors used an insulin test alone or with other tests.

Comment.-It seems reasonable to measure the acid secretion of patients with $x$-ray-negative dyspepsia, and it is surprising that physicians are reluctant to make this their usual policy. There is little clinical justification for inflicting insulin tests on patients with $x$-ray-negative dyspepsia.

\section{Gastric Ulcer}

Two-thirds of the gastroenterologists used gastric secretion tests in patients with $x$-ray evidence of a gastric ulcer. Of this group, one in four physicians but three in five surgeons did tests usually $(\mathrm{P}<0.001)$. The tests were similar to those used in duodenal ulcer and $x$-ray-negative dyspepsia. It is again of note that $9 \%$ of the doctors used an insulin test alone or with other tests.

TABLE I-Patients with Duodenal Ulcer: Frequency of Tests

\begin{tabular}{ccc|c|c|c}
\hline \multicolumn{2}{c|}{ Tests Done } & \multicolumn{1}{c|}{108} & \multicolumn{1}{c|}{75} & 183 \\
Sustroenterologists \\
\hline Never
\end{tabular}

TABLE II-Patients with Duodenal Ulcer: Type of Tests Used by 144 Gastroenterologists

\begin{tabular}{|c|c|c|c|}
\hline $\begin{array}{l}\text { Pentagastrin } \\
105(73 \%)\end{array}$ & $\begin{array}{c}\text { Augmented } \\
\text { Histamine } \\
23(16 \%)\end{array}$ & $\begin{array}{l}\text { Histalog } \\
12(8 \%)\end{array}$ & Other \\
\hline $\begin{array}{ll}\text { Alone } & 31 \\
+\mathrm{B} & 60 \\
+\mathrm{I} & 1 \\
+\mathrm{B}+\mathrm{I} & 13\end{array}$ & $\begin{array}{lr}\text { A.H.T. } & 12 \\
+\mathbf{B} & 8 \\
+\mathrm{B}+\mathrm{I} & 1 \\
+\mathrm{B}+\mathrm{gruel} & \mathbf{1} \\
\text { Infusion } & \mathbf{1}\end{array}$ & $\begin{array}{cc}\text { Alone } & 4 \\
+ \text { B } & 8\end{array}$ & $\begin{array}{l}\text { Test meal } 2 \\
\text { Insulin 1 } \\
\text { Basal alone } 1\end{array}$ \\
\hline
\end{tabular}

Comment.-There is little justification for measuring the acid secretion of patients with gastric ulcer, as there is no evidence that such measurements indicate the clinical course, the need for surgery, or whether the ulcer is benign. There is no justification for inflicting insulin tests on patients with gastric ulcer.

\section{E. Asymptomatic Patients after Partial Gastrectomy}

One-fifth of the surgeons performed acid tests at least sometimes in symptom-free patients in the year after partial gastrectomy, usually at about six months. Almost all these surgeons measured the peak acid output, and almost half of them used an insulin test.

Comment.-Little can be gained by measuring the acid secretion of asymptomatic patients after partial gastrectomy, and nothing gained from an insulin test.

\section{F. Dyspepsia after Partial Gastrectomy}

Four out of five gastroenterologists performed acid tests on patients with recurrent dyspepsia after partial gastrectomy. Only one-quarter of the physicians but three-quarters of the surgeons of this group performed tests usually, significantly less frequently than the three-quarters of the surgeons $(P<0.0001)$. The tests were similar to those used in the other patient groups. It is of note that one-seventh of those who used tests employed an insulin test.

Comment.-It seems reasonable to measure the acid secretion of patients with dyspepsia after gastric resection, and it is again surprising that physicians are reluctant to make this their usual policy. There is no justification for doing insulin tests on these patients.

\section{G. Asymptomatic Patients after Vagotomy}

Half the surgeons did not perform acid tests in symptom-free patients after vagotomy and only one-third carried out these tests usually. The timing of these tests varied from one week to one year after operation, most often at 2-12 weeks, but of the remainder an equal number performed them early (1-2 weeks) and late (26-52 weeks). Of the 41 surgeons who did such tests 38 specified those used, all of which were insulin tests. Half these surgeons also measured peak acid output, usually with pentagastrin; they also measured basal acid output. Thus the commonest procedure was insulin test alone (16) or basal acid output plus peak acid output plus insulin (14).

Comment.-It seems reasonable to measure acid secretion in all patients after vagotomy to assess the technique of the surgeon as well as the prognosis of the patient. There is no general agreement about which acid tests should be used; but basal acid output should always be measured, and probably also an insulin test and possibly a pentagastrin test.

\section{H. Patients with Recurrent Dyspepsia after Vagotomy}

Only 95 of the 108 physicians performed acid tests on patients with recurrent dyspepsia after vagotomy, and less than half of these performed them usually. All but one of the surgeons performed these tests and almost all performed them usually (Table III).

Of the physicians who did these tests, only three-quarters used an insulin test, and one-half of these were without basal acid output; about half measured peak acid output (usually with pentagastrin) with their insulin tests. The 21 physicians who did not use insulin mostly measured peak acid output 
( \pm basal acid output), but one physician measured only basal acid output, and another used a gruel test meal (Table IV). Of the 74 surgeons who measured acid, all but nine used the insulin test. More than half of these tests were with basal acid output; more than half the surgeons measured peak acid output (usually with pentagastrin) with their insulin tests. The nine surgeons who did not use insulin mostly measured peak acid output ( \pm basal acid output) but one surgeon used a gruel test meal (Table IV). Thus the surgeons performed acid tests in patients with postvagotomy dyspepsia significantly more often than did physicians; they performed them usually, and used insulin.

Comment.-All patients with dyspepsia after vagotomy should have their gastric acid measured, and this test should be a basal acid output, probably with an insulin test, and possibly also with peak acid output.

\section{Indication for Surgery in Duodenal Ulcer Patients}

More than half the physicians and two-thirds of the surgeons were influenced at least sometimes by acid tests in deciding whether a patient with duodenal ulcer should be advised operation. The surgeons were again significantly more intensive investigators than the physicians $(P=0-027)$. Of the 108 doctors who were influenced by acid tests 67 specified high peak acid output and six a high basal acid output as their criteria. Thirty-three specified the exact level of peak acid output above which they advised surgery, and this level was normally distributed over the range $25-60 \mathrm{mEq} / \mathrm{hour}$, with a mode of $40 \mathrm{mEq} / \mathrm{hour}$. Of three doctors who specified a level of basal acid output, one mentioned $>6$ and the other two $>10 \mathrm{mEq} /$ hour.

Comment.-There are only limited data to suggest that in patients with duodenal ulcer, the higher the peak acid output the worse the prognosis. At present it seems reasonable that the indications for surgery in a patient with duodenal ulcer should (with the exception of the very rare Zollinger-Ellison syndrome) be clinical only. There is even less evidence of the value of basal acid output in prognosis.

Duration of Basal Collection in 94 Measurements $(65 \%)$

\begin{tabular}{c|c|c|c|c}
\hline 1 hour & $\begin{array}{c}1 \text { hour } \\
19(84 \%)\end{array}$ & $\begin{array}{c}3 \text { hours } \\
1\end{array}$ & 12 hours & $\begin{array}{c}1+12 \text { hours } \\
5\end{array}$ \\
\hline
\end{tabular}

A.H.T. = Augmented histamine test. $B=$ Basal. $I=$ Insulin.

TABLE III-Patients after Vagotomy with Recurrent Dyspepsia: Frequency of
Tests

\begin{tabular}{|c|c|c|c|c|}
\hline Tests Done & & & 108 Physicians & 75 Surgeons \\
\hline 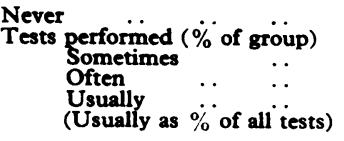 & $\begin{array}{ll}\cdots & \cdots \\
\cdots & \cdots \\
\cdots & \cdots \\
\cdots & \cdots\end{array}$ & $\begin{array}{l}\cdots \\
\ldots \\
\ldots \\
\cdots \\
\cdots\end{array}$ & $\begin{array}{l}13 \\
95(88 \%) \\
31 \\
19 \\
45 \\
47\end{array}$ & $\begin{array}{l}1(P=0.017) \\
74(99 \%) \\
8 \\
4 \\
62 \\
84(P<0.001)\end{array}$ \\
\hline
\end{tabular}

TABLE IV-Patients after Vagotomy with Recurrent Dyspepsia: Types of Tests

\begin{tabular}{|c|c|c|c|c|c|c|}
\hline \multicolumn{4}{|c|}{ Tests Specified by } & 92 Physicians & 74 Surgeons & $\mathbf{P}$ \\
\hline $\begin{array}{l}\text { All insulin } \\
\text { Insulin +B.A.O. } \\
\text { Insulin +P.A.O. } \\
\text { Pentagastrin } \\
\text { A.H.T. } \\
\text { Histalog } \\
\text { Not insulin } \\
\text { Basal+P.A.O. } \\
\text { P.A.O. } \pm \text { B.A.O. } \\
\text { Test meal } \\
\text { Basal only }\end{array}$ & $\begin{array}{r}\text { A.O. } \\
\text { A.O. } \\
\because \\
\because \\
\because \\
\because \\
\because \\
\because \\
\end{array}$ & $\begin{array}{l}\ldots \\
\cdots \\
\cdots \\
\cdots \\
\cdots \\
\cdots \\
\cdots \\
\cdots\end{array}$ & $\begin{array}{l}. \\
\cdots \\
\cdots \\
\cdots \\
\cdots \\
\cdots \\
\cdots \\
\cdots\end{array}$ & $\begin{array}{rr}71 & (75 \%) \\
35 & \\
32 & \\
& 23 \\
& 3 \\
& 6 \\
21 & \\
7 & \\
19 & \\
1 & \\
1 & \end{array}$ & $\begin{array}{lr}65 & (88 \%) \\
36 & \\
36 & \\
& 27 \\
& 8 \\
& 1 \\
9 & \\
4 & \\
8 & \\
1 & \\
0 & \\
& \end{array}$ & 0.005 \\
\hline
\end{tabular}

\section{J. Selective Surgery for Duodenal Ulcer}

Most physicians replied that the type of operation was decided by the surgeon to whom they referred the patient, so that the results of only the 75 surgeons have been analysed (Table V). Almost one-half of the surgeons were influenced by the results of acid tests in deciding the type of operation they used for patients with a duodenal ulcer. Only 16 of the 33 who used selective surgery specified their exact criteria. Almost all of these performed vagotomy and drainage in patients with lower peak acid output, and a more extensive operation, usually vagotomy and antrectomy, with higher acid outputs. The critical level of peak acid output ranged from 35 to $50 \mathrm{mEq} /$ hour, and the commonest figure was 50 $\mathrm{mEq} /$ hour. Four surgeons performed only a drainage operation if peak acid output was less than $25-30 \mathrm{mEq} / \mathrm{hour}$. Two surgeons always performed vagotomy in the presence of very high basal acid output.

Comment.-Though selective surgery for duodenal ulcer has been the policy since 1951, there is no evidence that such a policy has reduced mortality, ulcer recurrence rate, or postoperative sequelae. It seems reasonable to use one basic operation for patients with chronic duodenal ulcer regardless of acid output.

\section{Discussion}

Several gastroenterologists qualified their replies by explaining that they sometimes found it difficult to separate clinical from research indications in their use and choice of gastric function tests. With this proviso, we feel that the replies to our questionnaire provide a representative view of current practice.

We have discussed above the answers to each question in turn. In general, it does seem clear that the new, safe, and effective pentagastrin has largely replaced the older drugs as the stimulant of choice for evoking maximal acid secretion, and it can be prophesied that gruel meals, histamine, and Histalog will soon be abandoned completely. On the other hand, potentially dangerous insulin tests are being done in situations where they are unlikely to provide useful clinical (as opposed to research) information.

Fewer physicians than surgeons measure gastric acid secretion at all, and these physicians do so on fewer occasions. In some situations the conservatism of physicians may be justifiable-for example, in patients with dyspepsia not yet investigated and in those with gastric ulcers ( $A$ and $D$ above). In other situations, however, such as $x$-ray-negative and postoperative dyspepsia (C, F, and $H$ above) the greater investigative keenness of the surgeons is commendable. It is to be regretted that only half the surgeons ever try to assess the completeness of their vagotomies, and in only one-third of this half was it their usual practice. It is particularly surprising how many gastroenterologists do acid tests routinely on patients with $x$-ray evidence of duodenal ulcer, and are

TABLE v-Selective Surgery for Duodenal Ulcer: Tests Used by Surgeons

\begin{tabular}{|c|c|c|}
\hline \multicolumn{2}{|c|}{75 Surgeons } & Criteria Specified by 16 of 33 Surgeons Who Used Tests \\
\hline $\begin{array}{l}\text { Usually } \\
\text { Often } \\
\text { Sometimes } \\
\text { Never }\end{array}$ & $\begin{array}{r}7(9 \%) \\
5(7 \%) \\
21(28 \%) \\
42(56 \%)\end{array}$ & 14, P.A.O. $\left\{\begin{array}{c}<* \mathrm{mEq} / \mathrm{hr} \text { Vagotomy and drainage } \\
>* \mathrm{mEq} / \mathrm{hr}\left\{\begin{array}{l}\text { Vagotomy and antrectomy } 11 \\
\text { Partial gastrectomy } \\
\text { Vagotomy and Partial } \\
\text { gastrectomy }\end{array}\right.\end{array}\right.$ \\
\hline Min cosing test & (47) & $\begin{array}{l}\text { 4, P.A.O. < tmEq/hr Drainage only } \\
\text { 2, B.A.O. + + Vagotomy added to drainage } \\
\text { to partial gastrectomy (1) }\end{array}$ \\
\hline
\end{tabular}

* 35 (1), 40 (2), 45 (1), 50 (8) $\mathrm{mEq} / \mathrm{hr}$

N.B. Some surgeons used more than one criterion, so that the sums of several groups exceed the total. 
influenced by these acid tests in deciding whether these patients should have surgery and which type of operation should be done.

We are indebted to our gastroenterological colleagues for their kind co-operation in this inquiry. The support of J. H. B. by the Wellcome Trust is gratefully acknowledged.
Fuller details of the analysis can be obtained from the authors.

\section{References}

Baron, J. H. (1970). Scandinavian fournal of Gastroenterology, 5, Suppl. 6, p. 9. Duthie, H. L. (1969). In After Vagotomy, ed. J. A. Williams and A. G. Cox p. 225. London, Butterworths.

Williams, J. A. (1969). British fournal of Surgery, 56, 853.

\section{Appendix: The Gastric Questionnaire}

GASTRIC SECRETION STUDIES. In the following clinical problems please indicate in what percentage you employ gastric secretion studies, and signify in the
second line of columns the type of tests you customarily use.

